\title{
PRONOMES INDEFINIDOS
}

Afrânio da Silva Garcia (UERJ) afraniogarcia@gmail.com

\section{INTRODUÇÃO}

Os pronomes indefinidos constituem um dos pontos do conteúdo de língua portuguesa que apresentam mais dificuldade para um bom aprendizado, visto que compreendem vários tipos de vocábulos reunidos sob uma mesma denominação e são geralmente abordados de maneira pouco profunda nas gramáticas (por exemplo, Rocha Lima utiliza menos de uma página e meia, final da página 114 e página 115, para discorrer sobre o tópico, enquanto Manoel P. Ribeiro vai ainda mais além, finalizando o assunto em apenas um terço da página 170).

O objetivo da presente aula é justamente tentar fazer uma explanação sobre o assunto que tenha o rigor científico necessário e seja clara o suficiente para que, ao final dela, alunos das séries finais do $1^{\circ}$ grau ou alunos do $2^{\circ}$ grau sejam capazes de entender perfeitamente, classificar e usar os pronomes indefinidos do português.

\section{Definição}

A melhor e mais abrangente dentre as definições encontradas nas gramáticas pesquisadas foi a de José Carlos Azeredo: "Chamamse pronomes indefinidos as palavras gramaticais de significação imprecisa e não dêitica que integram o sintagma nominal" (cf. p. 124). Considerando-se que sintagma nominal é o nome técnico para cada parte de uma sentença que tem por núcleo um substantivo ou $\boldsymbol{e x}$ pressão substantiva e que dêitico significa "que aponta para uma determinada localização", podemos simplificar a terminologia excessivamente técnica do professor Azeredo e definir pronomes indefinidos como "palavras de significado impreciso ou indefinido que exercem a função de adjetivo (determinando um substantivo) ou de substantivo (substituindo um substantivo), mas não implicam uma ideia de localização", uma vez. A definição acima exposta, bastante fácil e abrangente, dá conta de todos os tipos de pronome indefinido 
que ocorrem no português. Para uma melhor compreensão, todavia, devemos especificar para os nossos alunos os vários tipos de imprecisão do significado ou de indefinição do significado compreendidos na denominação pronome indefinido.

\section{Tipos de pronomes indefinidos}

Os pronomes indefinidos podem ser divididos em vários tipos, de acordo com o tipo de indefinição de significado que eles expressam, quais sejam:

A) Inexistência ou ausência de um ser ou coisa - já que o fato de um ser ou coisa não existir num determinado contexto tornaos, de certa forma, indefinidos. Representada pelos pronomes $\boldsymbol{n e -}$ nhum, nenhuma (existem ainda os pronomes nenhuns e nenhumas, mas jamais são ouvidos, embora ocorram nos dicionários e gramáticas): algum e alguma (depois do substantivo); nada, ninguém e o arcaico nenhures (= em lugar nenhum).

Obs.: É importante notar que a palavra zero, muito embora também possa ser usada para indicar a inexistência ou ausência de um ser ou coisa, é um numeral, já que ela é usada de uma forma definida, em oposição aos demais números.

Da mesma forma, as palavras nunca e jamais também não constituem exemplos de pronomes indefinidos, já que têm função de advérbio e os pronomes indefinidos têm sempre função de adjetivo ou de substantivo.

B) Totalidade de um ser, coisa ou coletividade - quando se usa um termo para indicar a totalidade de um ser ou coisa ou de uma coletividade, em verdade ocorre uma indefinição do significado, uma vez que uma expressão como "todas as laranjas" ou "todo o bolo" não especifica quantas laranjas havia ou qual o tamanho do bolo. Representada pelos pronomes todo, toda, todos, todas, tudo, e o coloquial todo mundo.

Obs.: Certos adjetivos, como inteiro, total e completo, também dão essa ideia de totalidade, mas eles são usados num sentido mais definido, em oposição explícita ou implícita com seus antônimos: parcial e incompleto. 
C) Quantidade indeterminada de um ser ou coisa - indica uma quantidade de valor impreciso, variável de pessoa para pessoa. Assim sendo, a expressão "pouco dinheiro" terá um significado bem diferente para um senador e para um professor. Representada pelos pronomes algum, alguma (em expressões como algum dinheiro, alguma comida, equivalendo a um pouco), alguns, algumas, uns, umas (quando equivale a alguns, algumas); um pouco (de), pouco, pouca, poucos, poucas; muito, muita, muitos, muitas, demais; bastante, bastantes (forma restrita quase que exclusivamente aos dicionários e gramáticas), numerosos, numerosas; vários, várias, diversos, diversas, inúmeros, inúmeras; quanto, quanta, quantos, quantas; tanto, tanta, tantos, tantas; tamanho, tamanha, tamanhos, tamanhas; mais, menos.

Obs.1: A principal diferença entre os numerais e os pronomes indefinidos é que aqueles expressam uma quantidade determinada e estes expressam uma quantidade indeterminada de um ser ou coisa. Por isso, a palavra ambos, reminiscência do dual no português, é classificada como numeral e não como pronome indefinido: porque ela expressa uma quantidade determinada, equivalente a dois.

Obs.2: É importante não confundir alguns dos pronomes indefinidos que expressam quantidade indeterminada com certos advérbios de intensidade que têm a mesma forma, como muito, pouco, mais, menos, etc. Basta observar que classe de palavras esses termos estão determinando (qualificando, especificando, delimitando, etc.). Se as palavras muito, pouco, mais, menos e similares estiverem determinando um substantivo, serão necessariamente classificadas como pronomes indefinidos; se estiverem determinando um verbo, um adjetivo ou um advérbio, deverão ser classificadas como advérbios de intensidade.

Exemplos:

1) Ela trabalha muito. (advérbio de intensidade, pois está determinando trabalha, que é verbo)

2) Ele tem pouco tempo. (pronome indefinido, pois está determinando tempo, que é substantivo) 
3) Ele sentou-se muito confortavelmente. (advérbio de intensidade, pois está determinando confortavelmente, que é advérbio)

4) Faça menos barulho, por favor. (pronome indefinido, pois está determinando barulho, que é substantivo)

5) Ela é a mais bonita. (advérbio de intensidade, pois está determinando bonita, que é adjetivo)

D) Ser ou coisa indeterminada - quando não especificamos, dentro da coletividade de seres ou coisas idênticos, um determinado ser ou coisa. Representados pelos pronomes um, uma, uns, umas, algum, alguma, alguns, algumas; alguém, algo, algures (= em algum lugar); qualquer, quaisquer; determinado, determinada, determinados, determinadas, certo, certa, certos, certas; cada; qual, que, quem.

Obs.1: Vale a pena notar que certos pronomes indefinidos que indicam ser ou coisa indeterminada têm também um caráter distributivo, que pode ser geral ou particularizado. Assim sendo, os pronomes qualquer e quaisquer contêm esse caráter distributivo geral, indicando um ser na coletividade dos seres idênticos sem nenhuma caracterização individual, ao passo que os pronomes $\boldsymbol{d e}$ terminado e certo (e suas variantes) contêm um caráter distributivo particularizado, indicando um ser em particular dentro da coletividade de seres idênticos, ainda que indeterminado; já o pronome $\boldsymbol{c a}$ $\boldsymbol{d} \boldsymbol{a}$ (e suas variantes), reúne o caráter distributivo geral ao caráter distributivo particularizado, indicando todos os seres de uma determinada coletividade, mas individualizando-os através de alguma característica ou coisa que lhe é própria.

Exemplos:

6) Qualquer criança pode fazer isso. (uma criança, seja ela qual for, pode fazer isso)

7) Certa criança cismou de fazer bagunça. (uma criança em especial, ainda que indeterminada, cismou de fazer bagunça) 
8) Cada criança pegou seu baldinho e foi brincar na areia. (todas as crianças, cada uma em particular pegaram seu baldinho particular, e foram brincar na areia)

Obs.2: Os pronomes que, o que, quem, qual e quanto (e suas variantes), por serem frequentemente usados em sentenças interrogativas, são geralmente classificados como pronomes interrogativos na maioria das gramáticas, muito embora sejam igualmente frequentes em sentenças exclamativas. Minha opinião, ainda de acordo com o professor Azeredo, é que deveríamos classifica-los como "pronomes indefinidos que também podem ser usados para introduzir frases interrogativas e exclamativas".

Exemplos:

9) Qual é seu nome?

10) Quem é aquela garota?

11) Quantos anos você tem?

12) Quem diria!

13) Quanta tolice!

14) Que mulher bonita!

E) Alteridade - quando o pronome indefinido serve para indicar que um ser ou coisa é diferente ou não idêntico a um outro ser ou coisa, ainda que permaneça indeterminado. Representada pelos pronomes outro, outra, outros, outras, outrem (= outra pessoa), e o arcaico alhures (= em outro lugar).

\section{Pronomes indefinidos enfáticos}

Além dos pronomes indefinidos que acabamos de ver, existe uma série de locuções pronominais indefinidas, normalmente enfáticos, tais como:

quem quer que, o que quer que,

quem quer que seja, o que quer que seja,

qualquer um, qualquer que seja 


\section{FACULDADE DE FoRMAÇÃo de PROFESSORES}

onde quer que, onde quer que seja,

cada um, cada qual,

seja o que for, seja quem for, seja qual for,

\section{Exercícios}

I) Classifique as expressões grifadas como pronomes indefinidos ou advérbios de intensidade:

a) Já vi muito ódio.

b) Mais amor e menos confiança.

c) Ela é doida demais!

d) Comemos bastante.

e) Beba mais leite.

f) Quem pouco almeja, pouco consegue.

g) Ele é muito rápido.

h) Já viu tamanha cara de pau.

i) Muito bem!

j) Quer mais pimenta?

1) Eu te amo tanto !

II) Sublinhe os pronomes indefinidos:

—Venha cá! bradou o mestre.

Fui e parei diante dele. Ele enterrou-me pela consciência dentro um par de olhos pontudos; depois chamou o filho. Toda a escola tinha parado; ninguém mais lia, ninguém fazia um só movimento. Eu, conquanto não tirasse os olhos do mestre, sentia no ar a curiosidade e o pavor de todos.

— Então o senhor recebe dinheiro para ensinar as lições aos outros? Disse-me o Policarpo.

$-\mathrm{Eu} .$.

— Dê cá a moeda que este seu colega lhe deu! clamou. 
Não obedeci logo, mas não pude negar nada. Continuei a tremer muito. Policarpo bradou de novo que lhe desse a moeda, e eu não resisti mais, meti a mão no bolso, vagarosamente saquei-a e entreguei-lha. Ele examinou-a de um e outro lado, bufando de raiva; depois estendeu o braço e atirou-a à rua. E então disse-nos uma porção de coisas duras, que o filho e eu acabávamos de praticar uma ação feia, indigna, baixa, uma vilania, e para emenda e exemplo íamos ser castigados. Aqui pegou da palmatória.

— Perdão, seu mestre. . . solucei eu.

— Não há perdão! Dê cá a mão! Dê cá! Vamos! Sem-vergonha! dê cá a mão!

- Mas, seu mestre...

— Olhe que é pior!

Estendi-lhe a mão direita, depois a esquerda, e fui recebendo os bolos uns por cima dos outros, até completar doze, que me deixaram as palmas vermelhas e inchadas. Chegou a vez do filho, e foi a mesma coisa; não lhe poupou nada. Chamou-nos sem vergonhas, desaforados, e jurou que se repetíssemos o negócio, apanharíamos tal castigo que nos havia de lembrar para todo o sempre.

$\mathrm{Eu}$, por mim, tinha a cara no chão. Não ousava fitar ninguém, sentia todos os olhos em nós. (...)

(trecho de "Conto de escola" de Machado de Assis)

\section{BIBLIOGRAFIA}

AZEREDO, J. C. Fundamentos de gramática do português. Rio de Janeiro: Jorge Zahar, 2000.

BECHARA, E. Moderna gramática portuguesa. Rio de Janeiro: Lucerna, 1999.

. Moderna gramática portuguesa. São Paulo: Nacional, 1994.

CUNHA, C. F. Nova gramática do português contemporâneo. Rio de Janeiro: Nova fronteira, 1985.

LIMA, C. H. R. Gramática normativa da língua portuguesa. Rio de Janeiro: José Olympio, 1997.

RIBEIRO, M. P. Nova gramática aplicada da língua portuguesa. Rio de Janeiro: Metáfora, 2000. 